\title{
Trade and Wages: A Deeper Investigation
}

\author{
Ronald W. Jones* \\ Roy J. Ruffin \\ December, 2002
}

\begin{abstract}
A new presentation of the specific factors model shows how labor fares under international trade by considering how the price elasticity of the nominal wage rate responds to the terms of trade as well as factor endowments. Gains to labor are decomposed into measurable terms of trade effects and production bias effects. If trade is caused by differences in technology, trade can harm the interests of labor when the elasticities of substitution are sufficiently small. If trade is caused by differences in labor endowments, trade raises real wages in the labor abundant country, even if exports are capital intensive.
\end{abstract}

JEL Classification: F1

Key Words: Trade, Real Wages, Beta function, Specific Factors

Approximate Word Count: 8570

Jones: Xerox Professor, University of Rochester, Rochester, NY 14627, jonr@troi.cc.rochester.edu Ruffin: M.D.Anderson Professor, University of Houston, Houston, TX 77204, rruffin@uh.edu *The ordering of author names has been selected in order to avoid confusion with the referenced papers, Ruffin and Jones (1977), and Ruffin and Jones (2002). Each author claims equal input of the other author in these papers, regardless of any signal sent by the alphabet. 


\title{
Trade and Wages: A Deeper Investigation
}

\author{
Ronald W. Jones \\ University of Rochester \\ Roy J. Ruffin \\ University of Houston
}

When does international trade hurt workers? The classic answer provided by Wolfgang Stolper and Paul Samuelson (1941) presumed a Heckscher-Ohlin scenario in which only two commodities are produced with two productive factors completely mobile between sectors. The factor-intensity ranking of traded commodities told all, with real wages in the country importing the labor-intensive commodity unambiguously worsened if it should lower protective barriers to trade, while real wages in the exporting country would rise. ${ }^{1}$ This answer has proved popular not only because it is simple, but it also has minimal data requirements (Edward Leamer, 1998). However, there is another simple model that emphasizes the distinction between factors that are specific to individual sectors and a more mobile factor like labor (Ronald Jones, 1971 and Samuelson, 1971), a model that provides a richer set of criteria by which to judge the effect of trade on wage rates.

Specific factors are a pervasive phenomenon in production processes. Not only is capital specific in the short run in the form of equipment designed for particular products $^{2}$, there are many products for which factor specificity is a good first approximation. For example, oil fields, rice paddies, and coffee plantations may be

\footnotetext{
${ }^{1}$ This remark assumes that the same commodity is labor intensive in both importing and exporting countries. In the many-commodity case other outcomes are possible (Ronald Jones (2002).
} 
converted to other uses only when the prices of those products fall to very low levels ${ }^{3}$. Any degree of heterogeneity in land, capital, or labor yields to those factors economic rents in particular industries and thus lends the flavor of factor specificity to a broad range of factors. ${ }^{4}$ Common labor is perhaps the least specific of all factors, and so it seems appropriate to apply the specific-factors model to the impact of trade on a significant fraction of a nation's workers. ${ }^{5}$

In this specific factors model labor's nominal wage will be raised by an increase in either commodity price, but proportionally not by as much. Since the cost of living to workers would also increase, there emerges a neoclassical ambiguity about the effect of commodity price changes on the real wage rate. It was in this setting that twenty-five years ago Ruffin and Jones (1977) argued that there is a presumption that labor stands to gain in real terms by more open trade regardless of the trade pattern. However, a recent paper by James Melvin and Robert Waschik (2001) supplies a valuable computergenerated example in the specific-factors context that suggests that when elasticities of substitution in production are sufficiently low, mobile labor's real wage is depressed by any movement away from autarky. ${ }^{6}$ The effect of trade on real wages is obviously an important issue, and it is imperative that within the model characteristics of technology that can resolve the apparent conflict be laid bare even though many features of markets

\footnotetext{
${ }^{2}$ See Wolfgang Mayer (1974), Michael Mussa (1974) and J. Peter Neary (1978) for an analysis of short-run specificity of capital.

${ }^{3}$ Gottfried Haberler (1936, p. 194) points out the long-run factor specificity mainly in extractive industries.

${ }^{4}$ See Roy Ruffin (2001) for an analysis of quasi-specificity in a model with features both of the HeckscherOhlin and the specific-factors model.

${ }^{5}$ Both Ruffin (1981) and Jones and Stephen Easton (1983) show that the mobile factor in the specificfactors model may share many of the properties of a "middle" factor in the general three-factor, twocommodity model.

${ }^{6}$ Of course it has often been suggested that low elasticities of substitution in production may be detrimental to labor (for a survey see William Tyler, 1974), primarily if there is a promotion of capital-intensive import-competing activity. Note that in the Stolper-Samuelson model such elasticities do not count - only factor intensities matter.
} 
and economies outside the scope of the competitive specific-factors model also may be of relevance.

We present a framework for analyzing the specific factors model that pinpoints the characteristics that cause workers to gain or lose with trade. In addition to changes in the cost of living, the special relationship that turns out to be important is the function relating the price elasticity of the nominal wage rate to further changes in relative commodity prices (we call this the Beta function). Although our analysis is conducted for two sectors, it generalizes in simple fashion for any number of sectors. This research is important because it suggests some promising the empirical studies as well as policies that might be followed to ameliorate any losses workers might sustain from trade.

Section 1 reviews the foundations for studying the price elasticity of the wage rate. Section 2 introduces a new way to describe the specific factors model. We show that the gains to labor can be broken down into potentially measurable "terms of trade" and "production bias" effects. Section 3 analyzes in detail how, with constant elasticities of substitution, changes in prices or factor endowments affect wage gains when commodity prices change, and Section 4 concentrates on scenarios in which trade is damaging to workers. Section 5 allows world prices to be determined endogenously and shows that a result reminiscent of the Heckscher-Ohlin model extends to the specific factors model: If trade is caused by labor being the abundant factor, then labor will gain from trade. But if trade is caused by other factors, such as technology differences, trade can prove hazardous for labor. Section 6 summarizes the paper and makes some concluding remarks on future research. 


\section{Labor Intensity and Technological Flexibility with Specific Factors}

A deeper study of the specific-factors model can benefit from a reprise of what is already known (Jones, 1971; Mussa, 1974). Let commodities be labeled 1 and 2, and factors by $L$ for mobile labor, $K_{l}$ and $K_{2}$ the factors specific to each sector, $a_{i j}$ the inputoutput coefficients, $w$ and $r_{j}$ the nominal wage and rent in the $\mathrm{j}^{\text {th }}$ sector, and $p_{j}$ the $j^{\text {th }}$ commodity price. The requirement that labor be fully employed is shown in equation (1):

$$
\mathrm{a}_{\mathrm{L} 1} \mathrm{x}_{1}+\mathrm{a}_{\mathrm{L} 2} \mathrm{x}_{2}=\mathrm{L}
$$

Techniques are sufficiently flexible so that specific capitals are also fully employed:

$$
\mathrm{a}_{\mathrm{Kj}} \mathrm{x}_{\mathrm{j}}=\mathrm{K}_{\mathrm{j}}
$$

Each input-output coefficient depends upon the ratio of the wage rate to the return to the type of specific factor used in that sector. Indeed, the definition of the elasticity of substitution in a sector is provided by (3), where a "hat" over a variable indicates the relative change in that variable:

(3) $\sigma_{j} \equiv-\frac{\left(\hat{a}_{L j}-\hat{a}_{K j}\right)}{\left(\hat{w}-\hat{r}_{j}\right)}$

In the competitive profit relations, costs for each $x_{j}$ are driven down to price:

$$
a_{L j} W+a_{K j} r_{j}=p_{j}
$$

The input-output coefficients along the unit isoquant are selected so as to minimize unit costs of production at given factor prices, requiring:

$$
\theta_{L j} \hat{a}_{L j}+\theta_{K j} \hat{a}_{K j}=0
$$

with the $\theta_{\mathrm{ij}}$ denoting factor $i$ 's distributive share in industry $j$. Differentiating the competitive profit conditions, (4), and making use of (5): 


$$
\theta_{L j} \hat{w}+\theta_{K j} \hat{r}_{j}=\hat{p}_{j}
$$

Finally, the relative change in each input-output coefficient can be obtained by combining equation (5) with the definition of the elasticity of substitution in each sector given by equation (3):

$$
\hat{a}_{L j}=-\theta_{K j} \sigma_{j}\left(\hat{w}-\hat{r}_{j}\right) ; \quad \hat{a}_{K j}=\theta_{L j} \sigma_{j}\left(\hat{w}-\hat{r}_{j}\right)
$$

Return, now, to the full-employment condition (1). Output changes are obtained by differentiating (2) (yielding $\hat{x}_{j}=\hat{K}_{j}-\hat{a}_{K j}$ ), and a substitution into the differentiated form of equation (1) (with $\lambda_{\mathrm{Lj}}$ denoting the fraction of labor used in industry $j$ ), yields:

$$
\lambda_{L 1}\left(\hat{a}_{L 1}-\hat{a}_{K 1}\right)+\lambda_{L 2}\left(\hat{a}_{L 2}-\hat{a}_{K 2}\right)=\hat{L}-\left[\lambda_{L 1} \hat{K}_{1}+\lambda_{L 2} \hat{K}_{2}\right] .
$$

Substituting in the definition of the elasticity of substitution from (3):

$$
\lambda_{L 1} \sigma_{1}\left(\hat{w}-\hat{r}_{1}\right)+\lambda_{L 2} \sigma_{2}\left(\hat{w}-\hat{r}_{2}\right)=-\left\{\hat{L}-\left[\lambda_{L 1} \hat{K}_{1}+\lambda_{L 2} \hat{K}_{2}\right]\right\}
$$

The competitive profit equations of change, (6), can be re-arranged:

$$
\theta_{K j}\left(\hat{w}-\hat{r}_{j}\right)=\left(\hat{w}-\hat{p}_{j}\right)
$$

This relationship between changes in wage/rent ratio and wage/price ratios is useful in considering how the elasticity of demand for labor in the jth sector, denoted by $\gamma_{\mathrm{Lj}}$ and defined as (minus) the relative change in the labor/capital ratio with respect to a relative change in the wage/price ratio, is related to the elasticity of substitution in that sector. Thus combining equations (3) and (10):

$$
\gamma_{\mathrm{Lj}}=\sigma_{\mathrm{j}} / \theta_{\mathrm{Kj}}
$$

What equation (11) reveals is that even if elasticities of substitution are constant, the elasticities of demand for labor and the factor-intensity ranking will in general not be 
constant if factor prices change, with the value of the $\sigma$ 's indicating in which direction distributive shares move.

Throughout the paper we let the second commodity serve as numeraire, so that substituting back into equation (9) generates the final solution for the effect of a price change and endowment changes on the wage rate:

$$
\hat{w}=\beta_{1} \hat{p}_{1}+\left(\frac{1}{\gamma_{L}}\right) \hat{V}
$$

where $\quad \beta_{j} \equiv \frac{\lambda_{L j} \gamma_{L j}}{\gamma_{L}} ; \quad \gamma_{L} \equiv \lambda_{L 1} \gamma_{L 1}+\lambda_{\mathrm{L} 2} \gamma_{\mathrm{L} 2} ; \quad$ and $\hat{V} \equiv\left[\left(\lambda_{L 1} \hat{K}_{1}+\lambda_{L 2} \hat{K}_{2}\right)-\hat{L}\right]$

Thus the effect of an increase in the price of the first commodity on the nominal wage rate is a fraction, $\beta_{1}$, of the commodity price change. $\gamma_{L}$ represents the average elasticity of demand for labor in the economy and $\hat{V}$ the change in the aggregate capital/labor ratio. Clearly, $\beta_{1}+\beta_{2}=1$.

It is especially useful to rewrite the fraction, $\beta_{1}$, in a form that reveals the role of factor intensities and factor demand elasticities, on the one hand, and the output share of the first commodity, on the other. As is easy to show, $\beta_{1}$ can be expressed as the product of three parameters. ${ }^{7}$

$$
\beta_{1}=\left[i_{1} s_{1}\right] \theta_{1}
$$

Taking these in reverse order:

(i) $\theta_{1}$ is the share in national income represented by output in the first sector.

(ii) $s_{1}$ denotes the relative elasticity of demand for labor in the first industry, which is $\gamma_{\mathrm{L} 1} / \gamma_{\mathrm{L}}$. If there are only two sectors in the economy, this expression exceeds unity only

\footnotetext{
${ }^{7}$ See Jones (1989) or Richard Caves, Jeffrey Frankel and Jones (2002), p. S-21.
} 
if the elasticity of demand for labor in the first sector exceeds a comparable expression for the second. A rough way of referring to a situation in which $s_{l}$ exceeds unity is to say that sector 1 has the more flexible technology.

(iii) $i_{l}$ denotes the relative labor intensity in the first industry, indicated by the expression $\lambda_{\mathrm{L} 1} / \theta_{1}$. An intensity definition for labor involves a comparison of labor's distributive shares in the two sectors. It is easy to show that the term $\lambda_{\mathrm{L} 1} / \theta_{1}$ is the same as the expression $\theta_{\mathrm{L} 1} / \theta_{\mathrm{L}}$, a comparison of labor's distributive share in the first sector to

the average for the economy, $\theta_{\mathrm{L}}{ }^{8}$ Such an expression in the 2 -sector case exceeds unity only if labor's share in sector 1 is larger than in sector 2 .

Equation (13) makes clear that relative labor intensities always work in tandem with relative elasticities of demand for labor. We thus refer to $\left(\mathrm{i}_{1} \mathrm{~s}_{1}\right)$ as the intensityelasticity nugget. Given the interest that traditional trade theory accords the factorintensity ranking, we shall on occasion assume that such a ranking dominates in determining whether or not the size of the nugget exceeds unity.

\section{Real Wages and the Beta Function}

The real wage rate received by labor will be improved by an increase in the price of the first commodity if and only if the relative increase in the nominal wage rate, captured by the fraction, $\beta_{1}$, exceeds the increase in labor's cost of living, indicated by the share that the consumption of commodity 1 takes in labor's income. Call this share $\delta_{1}$. Thus the real wage increases if and only if as $p_{1}$ rises $\beta_{1}$ exceeds $\delta_{1}$ or, if $p_{1}$ falls, $\beta_{1}$ falls short of $\delta_{1}$ so that the cost of living falls more than the nominal wage rate. 
Without further restrictions on the taste pattern of laborers we are left with what has been termed the neoclassical ambiguity, the fact that changes in the terms of trade do not necessarily improve or lower the real wage rate. To help simplify matters, we now make an important assumption: Workers share the same homothetic taste pattern as possessed by all other agents in the economy. Later we sometimes assume an even more strict taste pattern for labor.

Given that an increase in the relative price of the first commodity improves the real wage rate if and only if $\left(\beta_{1}-\delta_{1}\right)$ is positive, it proves useful to decompose this term:

$$
\left(\beta_{1}-\delta_{1}\right) \equiv\left(\theta_{1}-\delta_{1}\right)+\left(\beta_{1}-\theta_{1}\right)
$$

The first term on the right-hand side represents the terms-of-trade effect. A positive value, revealing an excess of production of commodity 1 over consumption, implies that the country exports the first commodity and therefore benefits by an increase in its price. The terms-of-trade effect always operates to improve the real return to labor, given our assumption about labor's taste pattern. The second term has special significance for workers because it compares the increase in the nominal wage rate with the importance of the first commodity in overall production; $\left(\beta_{1}-\theta_{1}\right)$ is what we call the production bias effect, and it can be rewritten as $\left(\mathrm{i}_{1} \mathrm{~s}_{1}-1\right) \theta_{1}$.

Ruffin and Jones (1977) argued that there was a presumption that the real wage of workers would be improved by a rise in the price of exportables, so that mobile labor would be supportive of free trade. Their presumption was based on the fact that if exports were "typical" or "neutral" in terms both of labor-intensity and the elasticity of demand for labor by sector (that is both $i_{1}$ and $s_{1}$ were unity, or at least the nugget was),

\footnotetext{
${ }^{8}$ Let $\mathrm{Y}$ denote the value of output. Then $\lambda_{\mathrm{L} 1} / \theta_{1}=\left(\mathrm{X}_{1} \mathrm{a}_{\mathrm{L} 1} \mathrm{Y}\right) /\left(\mathrm{X}_{1} \mathrm{Lp} \mathrm{p}_{1}\right)=\left(\mathrm{wa}_{\mathrm{L} 1} \mathrm{Y}\right) /\left(w \mathrm{wL} p_{1}\right)=\theta_{\mathrm{L} 1} / \theta_{\mathrm{L}}$.
} 
the bias term would disappear so that $\beta_{1}$ becomes $\theta_{1}$ and the real wage would increase by moving to free trade. However, if the country does export the first commodity, but the nugget, $\left(\mathrm{i}_{1} \mathrm{~s}_{1}\right)$, is sufficiently smaller than unity, the bias effect might outweigh the favorable terms-of-trade effect, and increases in the relative price of exportables would in that case hurt labor.

For the moment let us make one further assumption about demand in order to focus on the production side of the question. This assumption is that labor and indeed all agents consuming in the economy possess Cobb-Douglas utility functions so that the consumption share for the first commodity, $\delta_{1}$, is a constant. As we proceed, we indicate how conclusions would need to be modified for more general homothetic tastes.

Turn, now, to the upper diagram in Figure 1. Recall that throughout we are holding constant the absolute price of the second commodity. The Cobb-Douglas assumption underlies the horizontal $\delta_{1}$ line. The production share $\theta_{1}$ curve must rise monotonically with $p_{1}$. The intersection of these two loci, where local demand and production are in balance (point $A$ ), establishes the price of the first commodity in autarky, $\mathrm{p}_{1}^{\mathrm{A}}$. It is the $\beta_{1}$ curve whose shape may be much less regular. For illustrative purposes the Beta function in Figure 1 rises for low prices and then turns down to intersect the $\theta_{1}$ curve at point $B$ and the $\delta_{1}$ line at point $E$ (and earlier at point $C$ ).

The lower diagram in Figure 1 explicitly shows the dependence of the real wage rate on relative commodity prices. As drawn, the $\beta_{1}$-curve lies above the $\theta_{1}$-curve at the autarky price. By (13) this means that for prices near autarky the value of the intensityelasticity nugget, $\left(\mathrm{i}_{1} \mathrm{~s}_{1}\right)$, exceeds unity, so that some exports of the first commodity unambiguously favor labor, while labor would lose if the country imports relatively small 
amounts of commodity one. Suppose world $p_{l}$ is greater than the autarky price. At point $B$ the bias term vanishes, and then works against labor for higher values of $p_{1}$. Between points $B$ and $E$ the terms-of-trade effect, $\left(\theta_{1}-\delta_{1}\right)$, outweighs the negative bias term, $\left(\beta_{1}-\theta_{1}\right)$ or $\left(i_{1} \mathrm{~s}_{1}-1\right) \theta_{1}$, so that the real wage still rises with increases in the export price.

We have assumed that the free-trade price is at $\mathrm{p}_{1}{ }^{\mathrm{T}}$. Labor clearly gains by free trade. Does this mean that labor would necessarily vote against protection? No, because a reduction in price to $\mathrm{p}_{1}{ }^{\mathrm{E}}$ would achieve a local maximum for the real wage rate.

Now consider the opposite trade pattern $\left(\mathrm{p}_{1}{ }^{\mathrm{T}}\right.$ lower than $\left.\mathrm{p}_{1}{ }^{\mathrm{A}}\right)$ so that the country would import good 1 . In the neighborhood of the autarky price the bias term indicates that labor would prefer the country to export the first commodity. Therefore price reductions down to $\mathrm{p}_{1}{ }^{\mathrm{C}}$ would lower the real wage; the bias effect outweighs the favorable terms-of-trade effect so that the reduction in the nominal wage rate is more severe than the drop in the cost of living. At even lower prices, however, the fall in $p_{1}$ leads to a terms-of-trade improvement (the country imports the first good) that becomes sufficiently powerful to outweigh the adverse effect of a positive value for $\left(\mathrm{i}_{1} \mathrm{~s}_{1}-1\right) \theta_{1}$ when $p_{l}$ falls. Point $C$ represents a minimum for the real wage.

Two aspects of the $\beta_{1}$ (Beta) function in Figure 1 should be emphasized - its height, and its shape. First of all, labor's interests are generally biased towards having the country export the first commodity because at autarky the crucial product, $i_{l} S_{l}$, exceeds unity. A basic asymmetry between the two sectors of the economy in autarky has been assumed, an asymmetry reflecting either sector 1 being labor intensive or having a more flexible technology, or a combination of the two. Secondly, as drawn, the extent of this bias changes with price increases. For prices higher than at $B$, the product, $i_{l} s_{l}$, 
becomes smaller than one. If the relative substitution term were "neutral", the laborintensity ranking would reverse at this point, with commodity 1 becoming capital intensive for higher values of $p_{1}{ }^{9}$ To focus on this second feature, in Figure 2 we assume an absence of bias in autarky, implying that the $\beta_{1}$ curve passes through the autarky intersection of the $\theta_{1}$ and $\delta_{1}$ curves. The value of the nugget, $i_{1} s_{1}$, unity at autarky, increases systematically with increases in $p_{1}$ in the $\beta_{1}$ ' curve, decreases systematically (but not too severely) in the $\beta_{1}{ }^{\prime}$ curve, and decreases so sharply in the $\beta_{1}{ }^{\prime \prime}$ curve that the curve actually becomes negatively sloped. In more detail:

(i) The $\beta_{1}$ ' curve: Labor unambiguously gains from trade regardless of the pattern of trade. What is the role of labor intensity? It is only one part of the $i_{1} s_{1}$ term that is monotonically increasing with $p_{1}$ (passing through unity at the autarky price). But suppose we (arbitrarily) invoke what can be called the "strong labor-intensity" assumption, viz., that the size of the product $\left(\mathrm{i}_{1} \mathrm{~s}_{1}\right)$ exceeds unity if and only if the relative labor-intensity term for the first sector, $i_{l}$, is itself greater than unity. This stacks the deck, as it were, in making the role of factor-intensity dominant. Consider the result along the $\beta_{1}$ curve: The country always exports its labor-intensive commodity, and labor always experiences an increase in its real wage from trade. This case indeed provides a strong connection between real wages and labor intensity, even stronger than in StolperSamuelson because here the country always exports its labor-intensive commodity.

(ii) The $\beta_{1}{ }^{\prime}$ curve: The strong labor-intensity assumption now implies that the first commodity is capital intensive for $p_{l}$ above the autarky price and labor intensive for prices below autarky. If we maintain our assumption that tastes are Cobb-Douglas, then

\footnotetext{
${ }^{9}$ Note that the relative labor intensity ranking could thus get reversed with price changes for an economy
} 
once again labor gains in real terms if the country exports the first commodity. What happens if the first commodity is imported, instead? Labor still gains in real terms since the nominal wage would fall by less than labor's cost of living. However, note that regardless of the trade pattern the country always imports its labor-intensive commodity. The result: The strong link between labor gains and labor intensity of exports is completely disrupted. And by assumption the blame cannot be laid at the feet of asymmetric substitution terms. As well, this case supports the neo-classical ambiguity about labor gains if we remove the assumption of Cobb-Douglas tastes and assume, instead, that demand curves for commodities are inelastic. The $\delta_{1}$ curve would become upward sloping, and might lie above the $\beta_{1}$ curve for some prices. Case (i) does not face this problem if we assume that there is a unique equilibrium point in autarky. ${ }^{10}$

(iii) The $\beta_{1}$ " curve: Here the decline in the size of the nugget, $i_{1} S_{l}$, as $p_{1}$ increases is so severe that the Beta function is negatively sloped. If tastes are Cobb-Douglas, labor must lose by trade, regardless of the trade pattern. Suppose the strong labor-intensity assumption is once again invoked. Then, as in case (ii), the country always imports its labor-intensive commodity, so that in Stolper-Samuelson fashion protection would always be applauded by labor if imports are labor intensive (and in this case they always are). If consumer tastes lead to elastic commodity demands, however, the $\delta_{1}$ curve also becomes negatively sloped, again opening up the neo-classical ambiguity so that labor might actually gain by trade.

As we now show, these cases are distinguished by the size of the elasticities of substitution in production in the two sectors. The $\beta_{1}$ ' curve is associated with elasticities

with given endowments. This phenomenon is ruled out in the Heckscher-Ohlin model. 
of substitution greater than unity, the $\beta_{1}$ " curve with elasticities smaller than unity but greater than some value that is less than $1 / 2$, while the negatively sloped $\beta_{1}$ "' curve is associated with substitution elasticities even smaller.

\section{The Case of Constant Elasticities of Substitution in Production}

The structure of the specific-factors model suggests that the adoption of the popular constant-elasticity-of substitution production function specification (CES) can aid in the analysis both of the slope of the Beta function and how changes in factor endowments cause the function to shift.

The benchmark case is the one in which the $\beta_{1}$-curve and the positively-sloped $\theta_{1}$ curve coincide: Production in each sector exhibits Cobb-Douglas technology with identical distributive shares for labor, with factor shares remaining constant with any change in relative commodity prices. The bias term always vanishes and the real wage always increases away from autarky. Furthermore, the strong symmetry between sectors suggests that neither an expansion of the labor force nor a balanced growth of sectorspecific capitals would shift the Beta function because outputs would both expand at the same rate. Of course an expansion in one specific factor alone would, at constant commodity prices, raise $\beta_{1}$ if and only if the first sector is the favored one.

A change in commodity price ratios has an effect on factor price ratios that is uniquely different to that found in the Heckscher-Ohlin model - wages rise relative to rents in one sector, but fall in the other. The effect this has on distributive factor shares and thus on the value of the intensity-elasticity nugget depends sensitively on whether the

\footnotetext{
${ }^{10}$ That is, with uniqueness of equilibrium the $\delta_{1}$ curve intersects the $\theta_{1}$ curve only once.
} 
elasticity of substitution in each sector exceeds or falls short of unity. In our joint query as to the slope of the Beta function and the manner in which this function shifts with endowment changes we turn, now, to the general range of possibilities.

First, suppose both $\sigma_{1}$ and $\sigma_{2}$ are larger than one. An increase in $p_{1}$ (with $p_{2}$ always constant) must lower the relative wage but raise labor's share in sector 1 and raise the relative wage but lower labor's share in the second sector. Thus unambiguously $i_{1}$ would increase. But so would the substitution term, $s_{1}$, in the CES case. The link between the elasticity of substitution and the elasticity of a sector's demand for labor is shown in equation (11), so that if the $\sigma$ 's are constant, a drop in $\theta_{\mathrm{K} 1}$ and an increase in $\theta_{\mathrm{K} 2}$ must serve to raise the relative elasticity of demand for labor in the first sector, $s_{l}$. (Incidentally, the values of the elasticities of substitution need not be the same between sectors). The consequence: The part of the bias effect indicated by $\left(\mathrm{i}_{1} \mathrm{~s}_{1}-1\right)$ must be increasing as the price of the first commodity goes up. (In Figure 2 this occurs with the $\beta_{1}$ 'curve, rising above and away from the $\theta_{1}$ curve.) High $\sigma_{i}$ 's imply that a rising export price serves increasingly to improve net benefits for labor.

A quite different scenario for the elasticity of the Beta function emerges when both elasticities of substitution are smaller than unity. An increase in sector 1's price, once again lowering the wage/rental ratio in sector 1 , now causes $\theta_{\mathrm{L} 1}$ to decline. By equation (11), a constant $\sigma_{1}$ now gets translated into a smaller value for the elasticity of demand for labor. ${ }^{11}$ With opposite changes taking place in sector two, both $s_{1}$ and $i_{1}$ fall.

\footnotetext{
${ }^{11}$ Strictly speaking it is not necessary to assume CES functions. A glance at equation (11) reveals that as long as the elasticity of substitution does not change as much and in the same direction as the capital share, the same qualitative results will hold.
} 
If the elasticity of substitution in one sector exceeds unity and in the other falls short of it, the relative values that are captured by both $i_{1}$ and $s_{l}$ might not change much so that any gap between the $\beta_{1}$ and $\theta_{1}$ curves would remain relatively unaltered.

If both elasticities of substitution are less than unity, could the increasing bias against labor in the $\left(\mathrm{i}_{1} \mathrm{~s}_{1}-1\right)$ term outweigh the positive terms of trade effect as the country exports the first commodity at ever better price? Yes, the $\beta_{1}$ curve could be negatively sloped, and a further bit of algebra helps to divulge the necessary conditions. ${ }^{12}$ As well, we show the effects of endowment changes in altering the value of $\beta_{1}$. Differentiating the expression for $\beta_{1}$ in equation (12) leads to:

$$
\hat{\beta}_{1}=\beta_{2}\left\{\left(\hat{\lambda}_{L 1}-\hat{\lambda}_{L 2}\right)+\left(\hat{\gamma}_{L 1}-\hat{\gamma}_{L 2}\right)\right\}
$$

The first term in brackets is clearly positive if $p_{l}$ rises, since labor will be transferred to the first industry. Using our earlier algebra, the explicit solution for this first term is:

$$
\left(\hat{\lambda}_{L 1}-\hat{\lambda}_{L 2}\right)=\left\{\beta_{1} \gamma_{L 2}+\beta_{2} \gamma_{L 1}\right\} \hat{p}_{1}+\left(s_{2}-s_{1}\right) \hat{V}+\left(\hat{K}_{1}-\hat{K}_{2}\right)
$$

The dependence of the second term on relative demand elasticities is easily explicable. Suppose the labor endowment rises at given commodity prices (thus lowering $V$ ). This lowers the wage rate and new labor is channeled to both sectors, but especially to the sector with the more flexible technology. If, instead, both capital supplies were to be increased in the same proportion, the wage rate would rise in both sectors, and labor would be drawn away from the more flexible sector. The role of the third term is obvious; a greater relative increase in the type of capital specific to the first sector would directly help to reallocate labor towards the first sector.

\footnotetext{
${ }^{12}$ This possibility emerges clearly in extreme cases not requiring extensive analysis (Ruffin and Jones, 2002).
} 
With CES functions assumed (not necessarily the same elasticity in the two sectors), the second term in brackets in (15) is given by $\left(\hat{\theta}_{K 2}-\hat{\theta}_{K 1}\right)$, which leads to:

$$
\begin{aligned}
\left(\hat{\theta}_{K 2}-\hat{\theta}_{K 1}\right) & =\left\{\beta_{1}\left(\frac{\theta_{L 2}}{\theta_{K 2}}\right)\left(\sigma_{2}-1\right)+\beta_{2}\left(\frac{\theta_{L 1}}{\theta_{K 1}}\right)\left(\sigma_{1}-1\right)\right\} \hat{p} \\
& +\frac{1}{\gamma_{L}}\left\{\left(\frac{\theta_{L 2}}{\theta_{K 2}}\right)\left(\sigma_{2}-1\right)-\left(\frac{\theta_{L 1}}{\theta_{K 1}}\right)\left(\sigma_{1}-1\right)\right\} \hat{V}
\end{aligned}
$$

Here the important role of the $\sigma$ 's versus unity in determining the direction in which distributive shares change is confirmed. Compare the role of these elasticities in the two coefficients. With a price change, the wage/rental ratio falls in one sector and rises in the other. Therefore if both elasticities exceed unity (or both fall short of unity), capital's distributive shares move in opposite directions in the two sectors, thus enhancing the difference in their changes. By contrast, suppose the labor endowment rises (a lowering of $V$ ). At constant prices this lowers the wage rate in both sectors, thus changing capital shares in the same direction if both $\sigma$ 's are either greater or less than unity.

Combining (16) and (17) into (15) yields the result we need to examine the effect of price or endowment changes on the price elasticity of wages, $\beta_{1}$ :

$$
\begin{aligned}
\hat{\beta}_{1}= & \beta_{2}\left\{\beta_{1} \frac{\left(1+\theta_{L 2}\right)}{\theta_{K 2}}\left[\sigma_{2}-\frac{\theta_{L 2}}{\left(1+\theta_{L 2}\right)}\right]+\beta_{2} \frac{\left(1+\theta_{L 1}\right)}{\theta_{K 1}}\left[\sigma_{1}-\frac{\theta_{L 1}}{\left(1+\theta_{L 1}\right)}\right]\right\} \hat{p}_{1} \\
+ & \frac{\beta_{2}}{\gamma_{L}}\left\{\frac{\left(1+\theta_{L 2}\right)}{\theta_{K 2}}\left[\sigma_{2}-\frac{\theta_{L 2}}{\left(1+\theta_{L 2}\right)}\right]-\frac{\left(1+\theta_{L 1}\right)}{\theta_{K 1}}\left[\sigma_{1}-\frac{\theta_{L 1}}{\left(1+\theta_{L 1}\right)}\right]\right\} \hat{V} \\
& +\beta_{2}\left(\hat{K}_{1}-\hat{K}_{2}\right)
\end{aligned}
$$

The form of the coefficients is striking both in the similarities and differences between price and endowment changes already noted in equation (17) and in the crucial 
comparison of each elasticity of substitution with a fraction that could never exceed $1 / 2 .{ }^{13}$

Thus for changes in commodity prices, a sufficient condition for the $\beta_{1}$ schedule to be positively sloped is that elasticities of substitution in production exceed one-half. ${ }^{14}$ In the coefficient of the $\hat{V}$ term, we notice (as in (17)) that since the wage/rental rate moves in the same direction in the two sectors, the shift in the Beta function, whether up or down, might be small if both $\sigma$ 's are greater than, or less than, unity.

\section{Possible Adverse Effects of Trade on Workers}

We started this paper by asking when international trade hurts workers. Now we have the necessary ingredients for the answer. Let the world price of the first commodity on world markets be higher than in autarky, with expectations that such a relative price will rise even more in the future, further encouraging greater globalization in the form of expanded exports of the first commodity. Because labor must gain by the terms-of-trade effect, it can be hurt by trade only if the bias effect, $\left(i_{1} s_{1}-1\right) \theta_{1}$, is sufficiently negative. ${ }^{15}$ A (damaging) small value for the intensity-elasticity nugget suggests some combination of relative labor intensity in the import-competing sector and relatively inflexible technology in the export sector. Furthermore, equation (18) reveals that if technological flexibility throughout the economy is severely limited (very small values for both $\sigma_{1}$ and $\sigma_{2}$ ), any further stimulus to exports given by rising prices can make matters even worse

\footnotetext{
${ }^{13}$ In the Melvin and Waschik (2001) paper, an example is provided where each sector's $\sigma$ has the same value of 0.4 and the same labor shares in autarky. This example is like Figure 2's $\beta$ "' curve, downward sloping and passing through the consumption share $\delta_{1}$ line at the autarky price.

${ }^{14}$ A question about the effects of technical progress on real wages that leads to somewhat similar conclusions was raised in Jones (1996).
} 
for labor. Although the economy would gain by an improvement in the terms of trade, labor would be left out - real wages would fall. Such low elasticities convert an improvement in the terms of trade into significant reductions in the value of the nugget, dragging the value of the price elasticity of wages, $\beta_{1}$, even lower.

Could an expansion of the economy's capital stock improve the prospects of such expanded trade for labor? The good news for labor is that at given terms of trade any increase in the stock of capital must serve to raise the wage rate. But what effect would it have on the position of the Beta function? Would this be shifted upwards, thus enhancing the effect of any further export price rise on the nominal wage rate? Clearly the composition of the increased capital stock makes a difference (see especially equation (16)); the more this favors the first sector the more apt is the $\beta_{1}$ curve to shift upwards (especially because of the positive effect on the share in production of the exportable sector, $\theta_{1}$ ). Neglecting this effect (by having a balanced expansion of capital in both sectors), the answer depends on the sign of the coefficient of $\hat{V}$ in equation (18), and two special cases in which the bias terms works against labor can be considered.

Suppose, first, that although labor intensities are the same between sectors, $s_{1}$ is smaller than unity (because $\sigma_{1}<\sigma_{2}$ ). As the wage rate rises with the balanced increase in capital stocks, labor moves towards export sector 1 , thus raising all three multiplicative components of $\beta_{1}$. Labor is thus favored for any further improvements in $p_{1}$.

By contrast, if the size of the nugget is small because it is the import-competing sector that is labor intensive $\left(\theta_{\mathrm{L} 2}>\theta_{\mathrm{L} 1}\right)$ while each sector exhibits the same value for its

\footnotetext{
${ }^{15}$ If $i_{1} s_{1}$ is smaller than unity, the bias effect becomes increasingly negative the larger is $\theta_{1}$. However, equation (14) reveals that the first (terms-of-trade) part of the expression $\left\{\left(\theta_{1}-\delta_{1}\right)+\left(\mathrm{i}_{1} \mathrm{~s}_{1}-1\right) \theta_{1}\right\}$ increases more with a rise in $\theta_{1}$ than would any negative bias effect (as long as $i_{1} s_{1}$ is positive).
} 
elasticity of substitution $\left(\sigma_{\mathrm{i}}=\sigma\right)$, the absolute size of this elasticity once again proves crucial. The criterion for the $\beta_{1}$-curve to shift upwards with a proportional increase in capital stocks becomes:

$$
\left(\theta_{\mathrm{l} 2}-\theta_{\mathrm{L} 1}\right)(\sigma-1 / 2)>0
$$

The increase in capital stocks increases the wage/rental ratio (at given $p_{l}$ ) by more in the labor-intensive import-competing sector $2 .{ }^{16}$ If common $\sigma$ is smaller than unity, capital shares fall in both sectors, but even more in sector 2 (as equation (17) confirms). Thus the values of both $i_{1}$ and $s_{1}$ fall even more from their initial values; criterion (19) reveals that if substitution elasticities are even lower than $1 / 2$, this reduction in $i_{1} s_{1}$ would drag the value of the $\beta_{1}$ elasticity down even though $\theta_{1}$ is increasing. ${ }^{17}$

The potential setting in which international trade could harm labor's real wage is thus found in situations in which the export sector is not intensive in its use of labor and/or exhibits a relatively low flexibility in its technology. As well, sufficiently low values for the elasticities of substitution could conspire to lower the price elasticity of wages, $\beta_{1}$, as terms of trade improve. A balanced increase in capital stocks would admittedly help labor by increasing the real wage rate for given commodity prices, but low elasticities would not help since they could cause the Beta curve to shift downwards.

On a more positive note, rents to the specific factor in the export sector are increased by trade. A signal is sent out to increase the supply of the specific factor, if possible, or to encourage technological change that will raise labor's productivity in the export sector. The so-called "green revolution" in agriculture provides an example in which a fixed

\footnotetext{
${ }^{16}$ With prices constant the wage rise, common to both sectors, must drive capital rentals down by more the higher is labor's distributive share.
} 
supply of land can nonetheless yield expanding outputs without requiring sharp drops in labor's marginal productivity. And the large volumes of trade in raw materials, which may serve as specific inputs in export sectors, also serve as responses to the signal of higher local rents. Although expanded trade may lead to concentrations in production and short-run gains to non-labor inputs that are temporarily rigid in their availability, such increases in rents signal supply changes over time that will work to benefit labor.

\section{Two-Country Trade}

Trade theorists may have noticed something odd about our preceding explanation of how trade or protection affects real wages, viz. nothing was said about the causes of international trade. The trading position depended only upon whether the exogenouslygiven world relative price of commodity 1 was higher or lower than the price ruling in autarky. If higher, the country exported the first commodity. In this section we analyze the case in which the only two trading economies share the same technology and endowments of specific factors. World prices are endogenously determined. If the endowment of labor abroad is smaller than it is at home, the home country can be considered to be the labor-abundant country. We also examine, albeit briefly, the case of trade caused by differences in technology.

What happens to the production ratio, $x_{1} / x_{2}$, when labor endowment $L$ changes and commodity prices are kept constant? We no longer need to assume a CES technology. Because each output is constrained by the (given) endowment of the specific factor used in that sector (equation (2)), the change in the ratio of outputs, is shown by:

\footnotetext{
${ }^{17}$ Before any labor-reallocation a balanced expansion of capital stocks causes output to expand by relatively more in the export sector because it is capital intensive. Additionally, the increase in the wage
} 


$$
\left(\hat{x}_{1}-\hat{x}_{2}\right)=\hat{a}_{K 2}-\hat{a}_{K 1}
$$

With earlier expressions for these terms, and noting that from $(12), \hat{w}=-\left(\frac{1}{\gamma_{L}}\right) \hat{L}$,

$$
\frac{\left(\hat{x}_{1}-\hat{x}_{2}\right)}{\hat{L}}=\frac{\theta_{L}}{\theta_{2}}\left\{i_{1} s_{1}-1\right\}
$$

Thus if the foreign country has a smaller labor force, the ratio of its production of the first commodity to that of the second will fall if, and only if, the bias term favors labor for increases in $p_{1}$. If it does, i.e. if $\beta_{1}$ exceeds $\theta_{1}$, abroad the autarky relative price of the first commodity will be higher than it is at home, and the resulting equilibrium world price, $\mathrm{p}_{1}{ }^{\mathrm{T}}$, will also exceed the home autarky price. If, instead, $\beta_{1}$ is smaller than $\theta_{1}$, the autarky price of the first commodity abroad would be lower than that at home and with trade the home country would import the first commodity.

These ideas are illustrated in Figure 3. The $\beta_{1}$ curve drawn there is downward sloping in order to represent the Melvin-Waschik finding that very low elasticities of substitution in production could spell trouble for real wages with trade. Home and foreign countries share the same technology and the same endowments of specific factors. Now consider autarky prices in the two countries with two alternative demand constellations (both Cobb-Douglas) represented by the $\delta_{1}{ }^{(1)}$ line and the $\delta_{1}{ }^{(2)}$ lines, common to both countries. If tastes support the upper $\delta_{1}{ }^{(1)}$ line, the home autarky price is shown by $\mathrm{H}^{(1)}$. With $\beta_{1}$ smaller than $\theta_{1}$, the foreign country, with a smaller labor endowment, will have an autarky price, $\mathrm{F}^{(1)}$, lower than at home. The free trade price lies between the two autarky prices, the home country imports the first commodity, and as a consequence its nominal wage rate is reduced by less than its cost of living so that real 
wages increase with trade. If tastes are shown by the $\delta_{1}{ }^{(2)}$ line, the autarky home price is $\mathrm{H}^{(2)}$. Because $\beta_{1}$ exceeds $\theta_{1}$, as the foreign country loses labor, the relative supply of the first commodity abroad is reduced and the foreign autarky price is higher than at home. The home country now becomes an exporter of the first commodity and, with $\beta_{1}$ exceeding $\theta_{1}$, the nominal wage rate increase exceeds the rise in labor's cost of living. Once again home real wages would rise. And these favorable outcomes for home real wages can be seen to hold as well if the $\beta_{1}$ curve is positively sloped.

The conclusion of this reasoning is that in the two-country case with countries differing only in their labor endowments, the labor-abundant home country's real wage rate must rise with free international trade. This is a strong result, because the laborabundant home country might export its capital-intensive commodity (it was only specified that the nugget exceeded or fell short of unity, not that $i_{l}$ necessarily did). Thus the labor-intensity comparison no longer provides the key either to income distribution or to the pattern of trade. Furthermore, it does not depend upon the size of elasticities of substitution. The basic notion that trade benefits the abundant factor is more general than suggested by the Stolper-Samuelson theorem and is impervious to the Melvin and Waschik critique.

If trade is caused by differences in technology, such as is typical between advanced and developing countries, the array of possibilities shown earlier when the world price ratio was exogenously given now also apply. And these results indicate that labor may indeed suffer with expansions of trade if substitution elasticities in production are relatively small in the export sector. For example, now both countries could in autarky be at a neutral position $\left(\mathrm{i}_{1} \mathrm{~S}_{1}=1\right)$ but at different autarky prices. Opening trade 
would thus hurt labor in both countries if $\beta_{1}$ is downward-sloping and help labor in both if upward-sloping, just as in Figure 2's $\beta_{1}{ }^{\prime \prime}$, and $\beta_{1}{ }^{\prime}$ curves, respectively. ${ }^{18}$

\section{Concluding Remarks}

The question of the effect of trade-related changes in commodity prices on the distribution of income, especially as regards the rewards to labor, has received prime attention both from trade theorists and from labor economists (e.g. Sue Collins, 1998). In this paper we shift attention away from the classic Stolper-Samuelson finding that a factor-intensity ranking tells all about trade and real wages and, instead, concentrate on investigating more thoroughly what the specific-factors model tells us about the possibilities of gains or losses to labor, considered to be mobile between sectors of the economy. A Beta function was defined, where the positive fraction, $\beta_{1}$, shows the relative increase in the nominal wage should the first commodity's relative price be increased. For any given terms of trade the height of the Beta function depends on the asymmetry between sectors of labor demand elasticities and labor intensities. However, these characteristics respond endogenously to changes in relative prices, in a manner that depends crucially on the size of elasticities of substitution in production. The presumption that labor gains by trade rests upon a positive terms-of-trade effect, just as for the economy as a whole. However, there is a production bias effect as well, working against labor either when the elasticity of substitution or labor intensity are relatively small in the export sector, or when elasticities in both sectors are absolutely small.

\footnotetext{
${ }^{18}$ Ruffin and Jones (2002) analyze technology differences in the simplified case in which production functions exhibit zero or infinite substitution elasticities, reaching the same conclusions.
} 
What has been said empirically about elasticities of substitution? In a careful study Alan Woodland (1975) argues for low elasticities in Canada. In Kenneth Arrow, et. al. (1961), elasticities were relatively high. More recently, Edward Balistreri, et. al. (2002), examine the possibility of Cobb-Douglas values in 28 industries, and find support in 20 of them. There is evidence of a broad range of estimates among industries, so that the asymmetries emphasized here may be very important. ${ }^{19}$ A systematic survey of techniques, countries and results would appear to be useful.

There is anecdotal evidence that trade might hurt labor in some developing countries. From 1980 to 1999, Mexico's exports as a percent of GDP increased from $10 \%$ to $30 \%$, but hourly wage as a fraction of per capita income fell by about $35 \%{ }^{20}$ Another example is provided by Thailand. From 1857 to World War II, rice production and exports increased more than twenty-fold. The terms of trade generally improved, but real wages fell while agricultural rents rose over the century (David Feeny, 1979). A recent survey by Matthew Slaughter (2000) concluded, “...there is a range of inequality outcomes.....But in a large number of cases, trade and FDI (foreign direct investment) liberalization were followed by rises in income inequality..." Empirical evidence consistent with the theory presented in this paper could well focus on the intensityelasticity nugget for export industries in developing countries.

Worker dissatisfaction with open markets can place political impediments in the transition to free trade. Since free trade is generally beneficial and over long periods appears to generate sizeable gains from learning and scale effects (David Gould and

\footnotetext{
${ }^{19}$ The ratio of highest to lowest elasticity was about 4 in Arrow, et. al. (1961), 6 in Tyler (1974), and 19 in Woodland (1975).

${ }^{20}$ Mexico's per capita income in current U.S. dollars was $\$ 3,409$ in 1980 and $\$ 5,060$ in 1999 . But hourly wages fell from $\$ 2.21$ to $\$ 2.12$.
} 
Ruffin, 1995), economists interested in promoting free trade need to pay attention to the possible problems arising from factor specificity and to the policies that could be followed to overcome them. 


\section{References}

Arrow, Kenneth. J., H. B. Chenery, B. S. Minhas, and R. M. Solow (1961). “CapitalLabor Substitution and Economic Efficiency," The Review of Economics and Statistics, 43, 225-250

Balistreri, Edward, Christine McDaniel, and Eina Wong (2002): “An Estimation of U.S. Industry-Level Capital-Labor Substitution Elasticities: Cobb-Douglas as a Reasonable Starting Point?”, unpublished.

Caves, Richard, Jeffrey Frankel and Ronald Jones (2002): World Trade and Payments: An Introduction, $9^{\text {th }}$ edition. (Addison Wesley, Boston).

Collins, Susan (ed.) (1998): Imports, Exports and the American Worker, (Brookings).

Feeny, David (1979). “Competing Hypotheses of Underdevelopment: A Thai

Case Study," Journal of Economic History, 39, 113-127.

Gould, David M. and Roy J. Ruffin (1995). "Human Capital, Trade, and Economic Growth," Weltwirtschaftliches Archiv, 131, 426-445.

Haberler, Gottfried (1936): Theory of International Trade, (Macmillan, New York).

Leamer, Edward E. (1998): “In Search of Stolper-Samuelson Linkages between International Trade and Lower Wages," in S. Collins (ed.), op. cit.

Jones, Ronald W. (1971): “A Three-Factor Model in Theory, Trade and History,” in J. Bhagwati, et. al. (eds.), Trade, Balance of Payments and Growth: Essays in Honor of Charles P. Kindleberger (North-Holland, Amsterdam).

(1989): “Co-movements in Relative Commodity Prices and International Capital Flows: A Simple Model," Economic Inquiry, pp. 131-41. (1996): “International Trade, Real Wages and Technical Progress: The 
Specific-Factors Model," International Review of Economics and Finance, v.5, n.2, pp. 113-34.

(2002): “Heckscher-Ohlin Models for the New Century,” in R. Findlay, L. Jonung, M. Lundahl (eds.), Bertil Ohlin: A Centennial Celebration (18991999), (MIT Press, Cambridge), pp. 343-62. and Stephen Easton (1983): “Factor Intensities and Factor Substitution

in General Equilibrium," Journal of International Economics, 15, 65-99.

Mayer, Wolfgang (1974): "Short-run and Long-run Equilibrium for a Small Open Economy," Journal of Political Economy, 82, 955-67.

Melvin, James and Robert Waschik (2001). "The Neoclassical Ambiguity in the Specific-Factors Model," Journal of International Trade \& Economic Development, 10, 321-337.

Mussa, Michael. (1974). "Tariffs and the Distribution of Income: The Importance of Factor Specificity, Substitutability, and Intensity in the Short and Long Run,” Journal of Political Economy, 82, 1191-1203.

Neary, J. Peter. (1978). "Short-Run Capital Specificity and the Pure Theory of International Trade," Economic Journal, 88, 488-510.

Ruffin, Roy J. (1981): “Trade and Factor Movements with Three Factors and Two Goods," Economic Letters, 7, pp. 177-82. (2001) : "Quasi-Specific Factors: Worker Comparative Advantage in the Two-Sector Production Model," Journal of International Economics, 53, 445-61. Ruffin, Roy. J. and Ronald W. Jones (1977). "Protection and Real Wages: the Neoclassical Ambiguity," Journal of Economic Theory, 14, 337-348. 
(2002): "Real Wages and Trade: Insights from

Extreme Examples," unpublished.

Samuelson, Paul A. (1971). "Ohlin was Right," Swedish Journal of Economics, 73, 365384.

Slaughter, Matthew J. (2000): "Trade and Labor-Market Outcomes: What about Developing Countries?" NBER Inter-American Seminar on Economics (July).

Stolper, Wolfgang. and Paul A. Samuelson. "Protection and Real Wages," Review of Economic Studies, 9, 58-73.

Tyler, William G. (1974): “Labour Absorption with Importing-Substituting Industrialization: An Examination of Elasticities of Substitution in the Brazilian Manufacturing Sector,” Oxford Economic Papers, 26, pp. 93-103.

Woodland, Alan D. (1975). “Substitution of Structures, Equipment and Labor in Canadian Production,” International Economic Review, 16, 171-187 


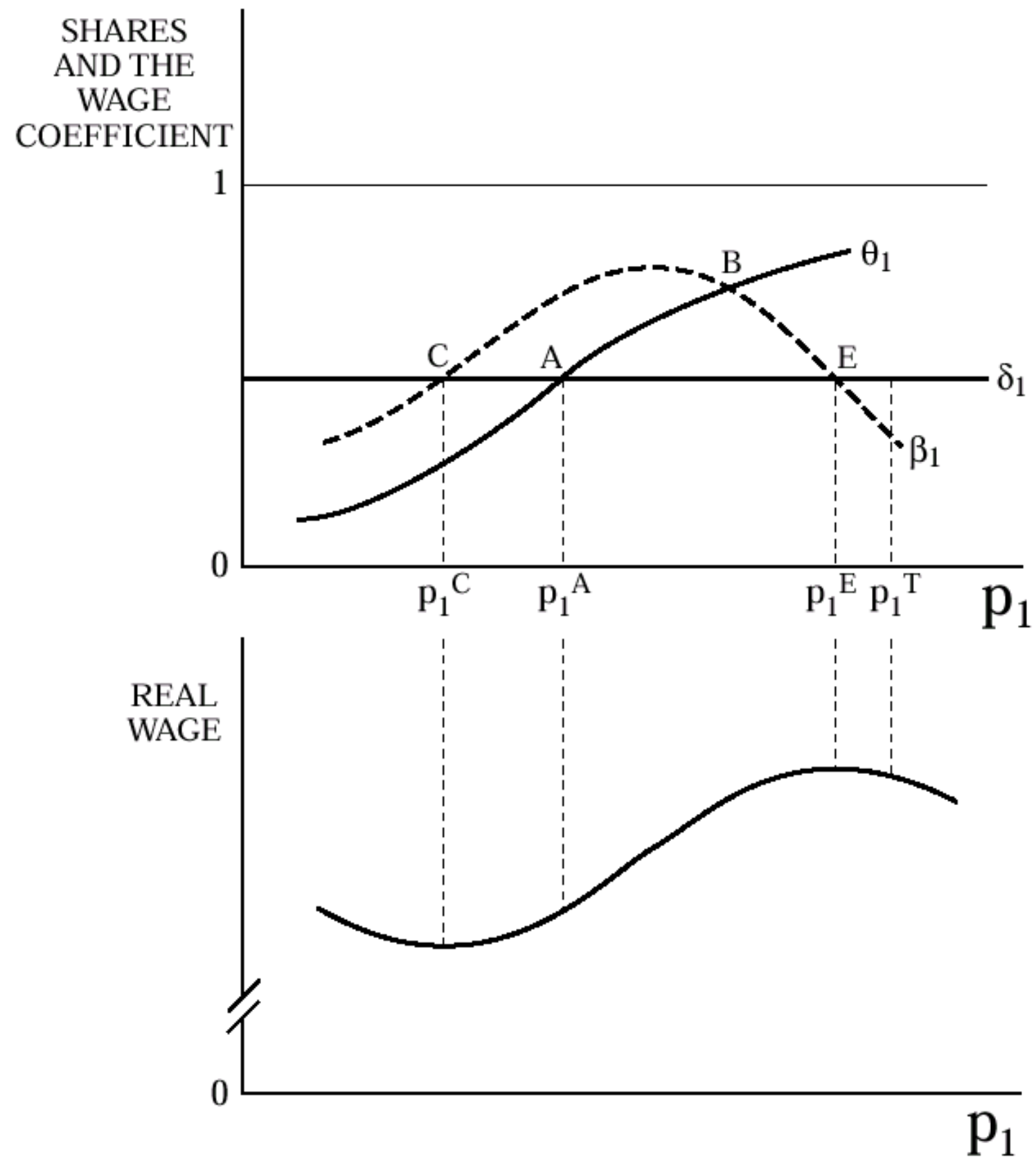

Figure 1: Free Trade, Protection and Real Wages 


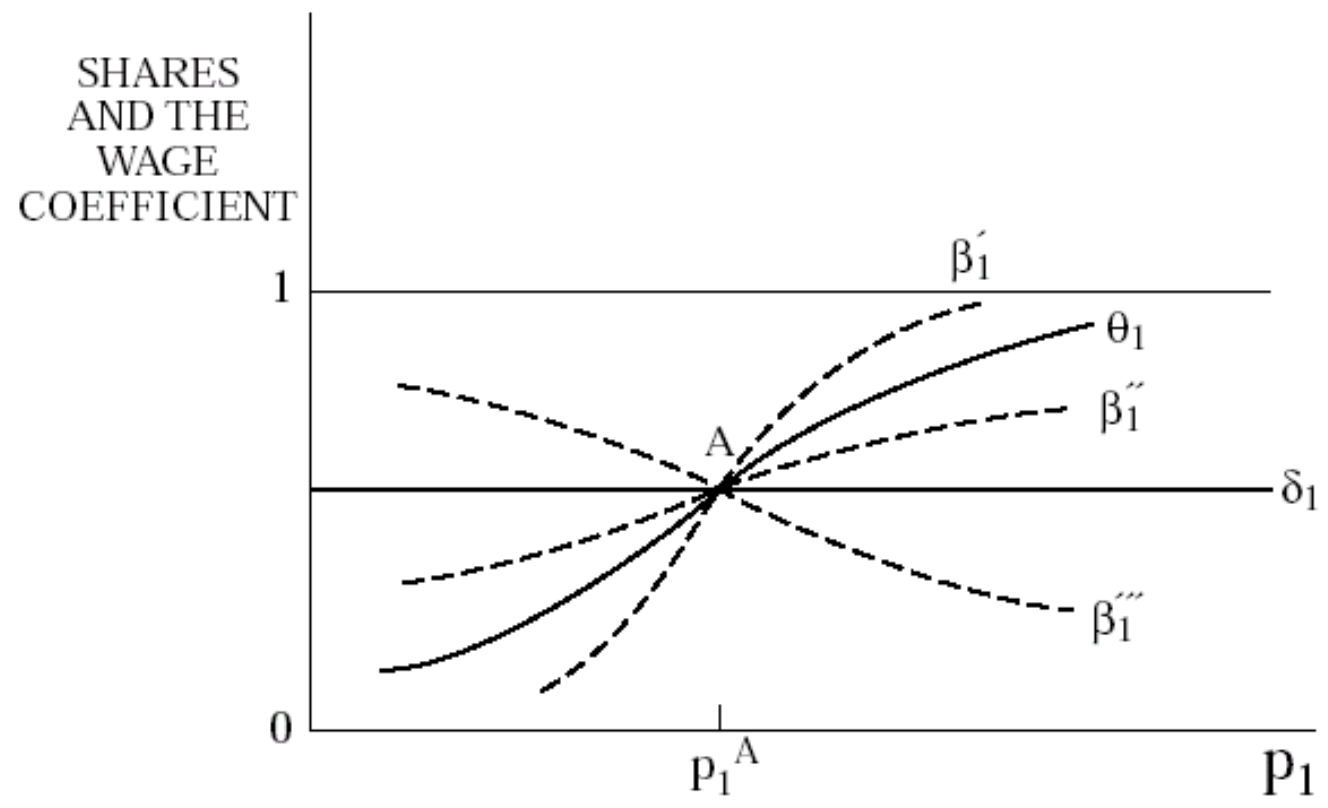

Figure 2: Alternative Wage Responses 


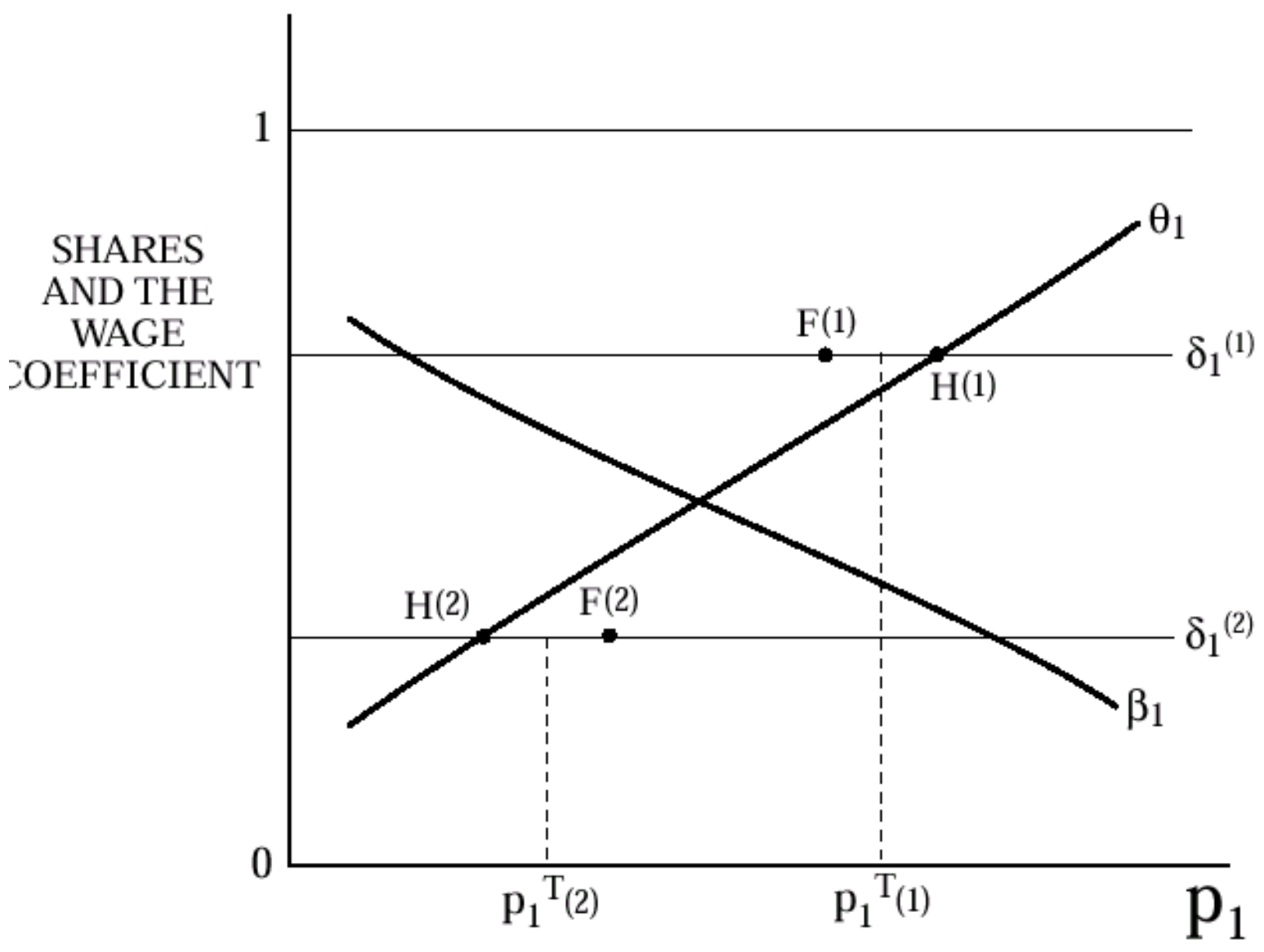

Figure 3: Two-Country Trade 